\title{
THE SOLAR FLARE EFFECT AT ALIBAG ON JUNE 13th. 1951
}

\author{
S. L. Malurkar
}

The magnetic Observatory at Alibag $\left(18^{\prime \prime} 38^{\prime} N, 72^{\prime \prime} 52^{\prime} E, 18\right.$ mile $S S E$ of Colaba, Bombay) is situated at a low magnetic latitude $\left(9^{\prime} .5\right.$ $N$ ). The variometers are usually run on a time scale of $15 \mathrm{~mm}, \mathrm{hr}$. Though the broad features of a magnetic phenomenon are recorded, the detailed profile during such periods can only be obtained when an open time scale is used. For the last few years, on special occasions, the instruments bave been run at $180 \mathrm{~mm} / \mathrm{hr}$.

It may just he possible to anticipate and put the quick-run in action for magnetic storms and be fortunate in obtaining detailed records of the same. Among the few phenomena that can hardly he anticipated at present is the solar flare effect or the 'Crochets'. Any such recording of the solar flare would be accidental. While the magnetic recorders had been on quick-run, on June 13th. 1951, a remarkable record was obtained. The solar flare effect commenced on the record at Alibay at 0546 GMT and the effect was over after about 140 minutes. Solar flares were visually recorded at Kanzelhöhe, Meudon, Zürich, Saltsjobaden and Herstmonceux about that time of the day. The particular observations corresponding to the crochet are:

\section{TABLE}

\begin{tabular}{|c|c|c|c|}
\hline Station & Time GMT & Importance & $\begin{array}{l}\text { Number of Active } \\
\text { Region of Quarter }\end{array}$ \\
\hline $\begin{array}{l}\text { Saltsjobaden } \\
\text { Kanzellohe } \\
\text { Meudon } \\
\text { Ziiricl } \\
\text { Ondrejov } \\
\text { Herstmonceux }\end{array}$ & $\begin{array}{l}0612 \\
06+1-0905 \\
06+1-0700 \\
0710-0725 \\
0713-1000 \\
0756-0801 \\
0759-0948 \\
0900-0906 \\
0910-0925\end{array}$ & $\begin{array}{l}3 \\
3 \\
1- \\
2- \\
2 \\
? \\
? \\
1 \\
1\end{array}$ & $\begin{array}{l}26 \\
26 \\
24 \\
26 \\
26 \\
26 \\
23 \\
24 \\
26\end{array}$ \\
\hline
\end{tabular}


Canberra reported flare, radio fade-out and ionospheric disturbance from 0550 GMT for 31 minutes on a large number of hands (60, 62, 73, 100, 1200 and $3750 \mathrm{Mc} / \mathrm{s})$. Tokyo had ionospheric disturbance from 0635 GMT for 100 minutes. (All the data above are from Ouart. Bull. Solar Activity. N. 94. 1951. Zurich).

In a letter, the All India Radio has said that as olsserved at Todapur (Delhi), there was complete radio fadeout of short and medium wave hands hetween 0550 and $0730 \mathrm{GMT}$ and that conditions started improving at $0840 \mathrm{GMT}$ and hecame normal at $0850 \mathrm{GMT}$.

From data of CRPL bulletins of the National Bureau of Standards, Washington (U.S.A.) the following table has been constructed.

TABLE

\begin{tabular}{|c|c|c|}
\hline $\begin{array}{l}\text { Receiving } \\
\text { Station }\end{array}$ & $\begin{array}{l}\text { Time } \\
\text { GMT }\end{array}$ & Localtion of Transmitters \\
\hline $\begin{array}{l}\text { Hongkong } \\
\text { (China) }\end{array}$ & $0555-0725$ & $\begin{array}{l}\text { China, England, Formosa, Frenth Indo-Chi- } \\
\text { na, Japan, Malay States, Philippine Ids., } \\
\text { Thailand. }\end{array}$ \\
\hline $\begin{array}{l}\text { Colombo } \\
\text { (Ceyloni) }\end{array}$ & 0555-0800 & China, England, India, Japan. \\
\hline $\begin{array}{l}\text { Lindau } \\
\text { (Harz-Germany) }\end{array}$ & $0550-1100$ & $\begin{array}{l}\text { Munichl, Lindau fpulse trasmitter and re- } \\
\text { reiver), Wiesbaden. }\end{array}$ \\
\hline $\begin{array}{l}\text { Brentwood } \\
\text { (Engliand) }\end{array}$ & $0600-0805$ & $\begin{array}{l}\text { Alghanistan, Austria, Bahrein Ids. Belgian } \\
\text { Congo, Bulgaria, Eritrea, Greece, India, } \\
\text { Iran, Kenyal, Malta, Palestine, Portugal, } \\
\text { S. Rhodesia, Spiain, Switzerland, Syria, } \\
\text { Thailand, Trans-Jordan, O.S.R., Yugosla- } \\
\text { via. }\end{array}$ \\
\hline $\begin{array}{l}\text { Somerton } \\
\text { (Englind) }\end{array}$ & $0600-0800$ & $\begin{array}{l}\text { Aden, Australia, Ceylon, China, Cyprus, } \\
\text { Formosa, India, Itnion of S. Africil. }\end{array}$ \\
\hline
\end{tabular}

The sub-solar point moved just soutl, of the Tropic of Cancer from the Indo-Burma horder to Oman. Alihag olsservatory was favourably situated for recording the crochet. The localities of the radio fade-out seem to fit a text book example of the area that should be affected.

On June. 14th at 1750 GMT a moderate maynetic storm started at Alihad with a s. c. of $25 r$ in $H$ and the storm lasted ahout 52 hours. 
The profile of the flare for the horizontal and vertical magnetic components and declination is given after taking out the effect of diurnal variation (Tahle and Diagram).

\section{TABLE}

\begin{tabular}{|c|c|c|c|}
\hline & \multicolumn{3}{|c|}{ Relative displacement from values at 05.46 GMT } \\
Trorrected for diurnal vartation)
\end{tabular}

The variation in $D$ is very small on most occasions, at Alibag. The decimal point firures are given to help to draw the resultant curve.

The main feature to notice is the fact that the rise to the maximum has been in two stages, with an inflection between 0621 and 0626 GMT. The maximum was attained at 0632 GMT. The active regions of flares that were observed (nos. 23,24 and 26 of the quarter) crossed the central meridian of the sun on June. 7.9. 11.8 and 18.3. As the flare corresponding to active region $n$. 23 was observed at Ondrejov between 0759 and 0948 GMT, the crochet recorded at Alibag is due to flares of the active regions $n$. 24 and n. 26 and the two stages 
step to the maximum, which is equivalent to two superposed maxima, is due to two distinct flares.

Most of the radio fade-outs have been reported 4 minutes after the crochet at Alibag commenced. The ionospheric disturbance at Tokyo has been reported about three to four minutes after the absolute maximum of the crochet was reached at Alibag. Though one should be reluctant to use the $V$ records in these latitudes, it may be pointed out that from 0546 to 0551 GMT there has been little change and that from 0720 to 0730 GMT there has been a fattening

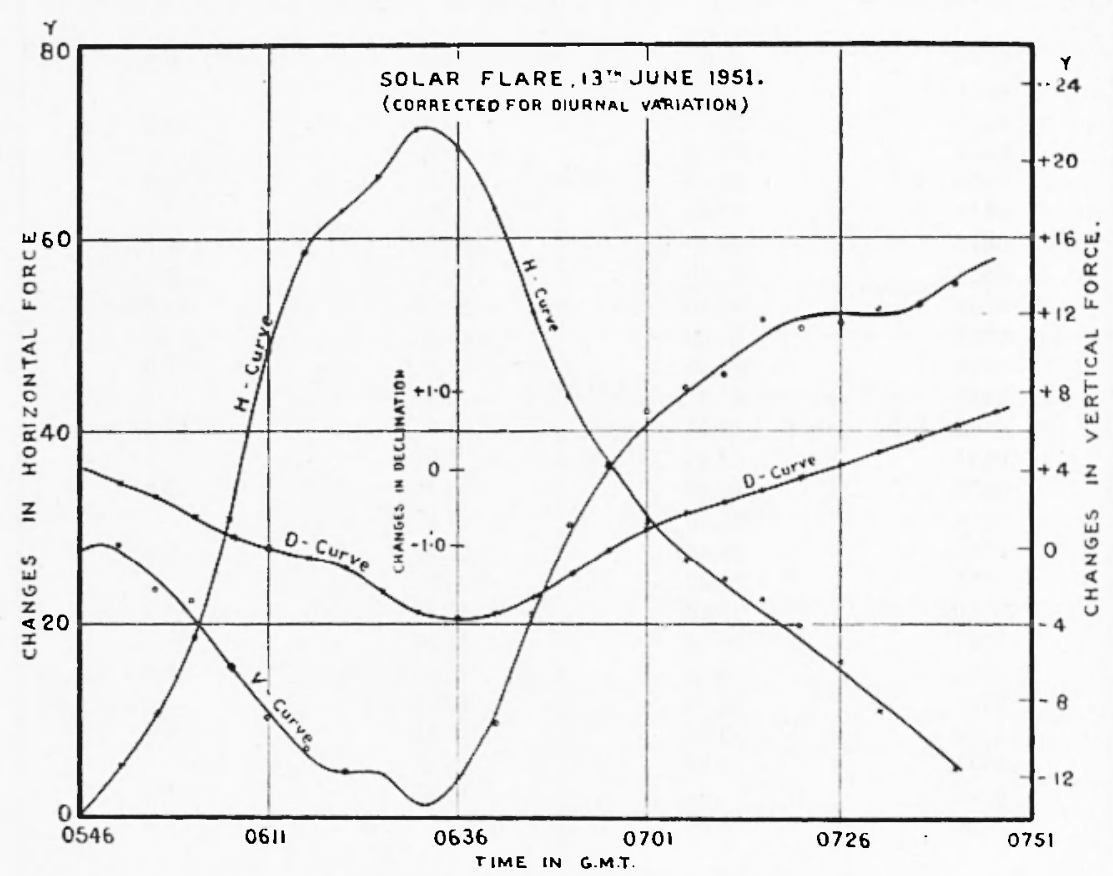

Fig. 1

in the smoothed $V$ curves. Whether this has anything to do with the period of complete fade-out of stations as received at Delhi 10550 to 0730 GMT) cannot be definitely said.

The detailed correlation of the profile can only be done if any other institution ha: collected cognate data on a comparable time scale.

From the publications of the Norske Institutt for Kosmisk Fysik (Nr. 34. observations of 1951 ), it is noticed that the daily range of 
Ozone at Troms $\varphi$ were much larger on the 13th and 14th June. 1951 $0.19 \mathrm{~mm}$ and $0.36 \mathrm{~mm}$ respectively while the average diurnal range for the inonth was only $0.08 \mathrm{~mm}$.

The recording was done by Mr. A. S. Chaubal and Mr. D. K. Deshmukh and help was rendered in calculations by Mr. M. Panduranga Rao and Mr. K. S. Raja Rao.

Colaba Observatory. — Bombay. 5. Jan. 21st. 1953.

\section{$S U M M A R Y$}

A detailed study of the quich-run magnetograms of the Solar Flare of June 13, 1951. Alibag uas favourably situated. Corresponding to different flares on that day the profile of the solar flare effect has a two-stage maximum. The time of the onset of the radio fade-out in relation to the flare has been pointed out. In the vertical force, effect corresponding to the onset and end of radio fadreout there has been a temporary no-variation-uith-time stage or a sort of inflexion. The diurnal rang of ozone at Tromso also uas abnormally large within the next 24 hours. 